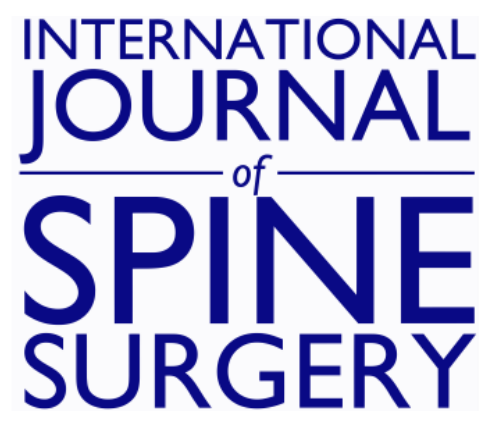

\title{
Twelve-Month Follow-up of Lumbar Spine Range of Motion Following Intervertebral Disc Replacement Using Radiostereometric Analysis
}

Nathaniel R. Ordway, Amir H. Fayyazi, Celeste Abjornson, Jerry Calabrese, Soo-An Park, Bruce Fredrickson, Kenneth Yonemura and Hansen A. Yuan

Int J Spine Surg 2008, 2 (1) 9-15

doi: https://doi.org/10.1016/SASJ-2007-0115-RR

http://ijssurgery.com/content/2/1/9

This information is current as of April 26, 2023.

Email Alerts Receive free email-alerts when new articles cite this article. Sign up at: http://ijssurgery.com/alerts

The International Journal of Spine Surgery 2397 Waterbury Circle, Suite 1, Aurora, IL 60504, Phone: +1-630-375-1432 


\title{
Twelve-Month Follow-up of Lumbar Spine Range of Motion Following Intervertebral Disc Replacement Using Radiostereometric Analysis
}

\author{
Nathaniel R. Ordway, MS, PE, Amir H. Fayyazi, MD, Celeste Abjornson, PhD, Jerry Calabrese, RT(R), CDT, \\ Soo-An Park, MD, Bruce Fredrickson, MD, Kenneth Yonemura, MD, and Hansen A. Yuan, MD
}

\begin{abstract}
Background

Many clinical studies have focused on clinical pain scores and less on kinematics following intervertebral disc replacement. Although flexion and extension of the motion segment can be measured on lateral X-rays, measuring lateral bending and axial rotation of the device is extremely difficult on plain radiography. This study was designed to measure, using radiostereometric analysis (RSA), the postoperative range of motion of the spinal segment following placement of ProDisc-L interbody device (Synthes Spine, West Chester, Pennsylvania).
\end{abstract}

\section{Methods}

Twelve patients (15 discs) with a ProDisc-L intervertebral disc replacement were followed postoperatively at 1.5, 3, 6, and 12 months with both clinical and RSA examinations. For follow-up RSA analysis, 4 to 5 tantalum beads were inserted into the vertebrae adjacent to the surgical level during surgery. Standing biplanar films were collected during follow-up, and the ranges of motion (ROM) (sagittal and coronal bending) of the adjacent vertebrae were determined by RSA.

\section{Results}

Based on the clinical surveys, this group of patients had similar outcomes compared to larger clinical populations. The flexion/extension ROM with the disc replacement averaged $2.5^{\circ}$ at 6 weeks and increased over the follow-up period to $6.6^{\circ}$ at 6 months. The lateral bending ROM with the disc replacement remained consistent over the 4 time points and averaged $3.0^{\circ}$. The motion at the level of the L4-5 vertebrae following disc replacement was greater across all time points than the motion at the L5-S1 level for both sagittal $\left(5.9^{\circ}\right.$ versus $\left.2.1^{\circ}\right)$ and coronal $\left(4.2^{\circ}\right.$ versus $\left.0.6^{\circ}\right)$ bending.

\section{Conclusions}

In this study, the amount of RSA-measured segmental flexion/extension ROM for those with disc replacement was similar to other studies using plain radiography. In lateral bending, the amount of motion with disc replacement was less than the typical $6^{\circ}-16^{\circ}$ reported for normal ROM.

\section{Clinical Relevance}

This is the first published study evaluating the in vivo kinematics of artificial disc replacement using RSA.

Key Words: Kinematics, ProDisc-L, range of motion, radiostereometric analysis. SAS Journal. Winter 2008. 2:9-15. DOI: SASJ-2007-0115-RR

\section{INTRODUCTION}

Spinal fusion has been an effective technique for treatment of lumbar pathologies for more than 100 years. ${ }^{1-3}$ It allows the removal of the pathological lesion, correction of deformity, stabilization of instability, and decompression of neural elements. Spinal fusion has consequences, including loss of motion and transfer of additional stress on the adjacent segments, which may result in progression of degenerative process and clinical symptoms. ${ }^{4-6}$

The desire to restore functional motion has long been the driving theme in orthopaedic surgery and has recently become more prominent in spine surgery. Lumbar disc arthroplasty is one technique that has the potential of maintaining spinal motion by replacing the degenerative lumbar disc with a mechanical implant. The advantages of using a total disc replacement is the removal of painful disc, restoration of disc height resulting in secondary decompression, and maintenance of segmental motion with a potential reduction or delay in the incidence of adjacent-level degeneration..$^{7-9}$

The first known spine arthroplasty procedure was performed by Fernström when he implanted a metallic ball into the disc space via a posterior approach. ${ }^{10}$ The first generations of Charité artificial lumbar discs were implanted in Germany in the mid 1980s. ${ }^{11}$ In 1990, Thierry Marnay, MD, began implanting the 
first generation of ProDisc, a semi-constrained implant that he developed in France. ${ }^{12}$ Between 1990 and 1993, 64 patients underwent single- or multi-level total disc replacement with ProDisc I. ${ }^{12}$ Marnay recently reported 7- to 11-year follow-up of these patients and found $75 \%$ reported good to excellent results. ${ }^{12}$ The second generation ProDisc implant, the ProDiscL (Synthes Spine, West Chester, Pennsylvania), maintained the basic concepts of the previous design, although some changes were made. The ProDisc-L has a single, centrally located keel, a titanium plasma-spray coating on the surfaces exposed to the boney endplates, a nitrogen-packed ultra-high molecular weight polyethylene (UHMWPE) modular inlay, and a bearing surface made of UHMWPE and cobalt-chromium alloy. ${ }^{13}$

Two prospective, randomized, multicenter US Food and Drug Administration investigational device exemption (IDE) clinical trials were performed to determine the safety and efficacy of the ProDisc-L total disc replacement versus $360^{\circ}$ fusion at either 1 level or 2 levels from L3 to the sacrum. The hypothesis of the IDE trials was that patients receiving a total disc replacement would experience clinical success not inferior to randomized control patients undergoing anterior-posterior $\left(360^{\circ}\right)$ spinal fusion. ${ }^{12,14}$

These studies, in addition to other clinical studies that have examined intervertebral disc replacements, have focused more on clinical pain scores and less on kinematics following implantation. ${ }^{15,16}$ Assessment of segmental spine motion has been, and continues to be, a difficult clinical problem. Errors of up to $5^{\circ}$ for simple measurements of flexion, extension, and side bending have been recorded using conventional radiographs. ${ }^{17-19}$ These errors are usually associated with the inability to acquire three-dimensional positions and inaccurate reference points. It has therefore been extremely difficult to measure small changes in vertebral alignment.

Radiostereometric analysis (RSA) is an accurate in vivo measurement technique using two simultaneous radiographs. ${ }^{20,21}$ It provides researchers with 3-dimensional motion analyses to look at not only routine flexion/extension, but also other rotational and translational changes. The measurement accuracy offered by this technique far exceeds the manual techniques currently used. Preliminary work on the accuracy, reliability, and surgical planning for use of RSA has demonstrated an accuracy of 100 micrometers of translation and $0.5^{\circ}$ of motion. ${ }^{22}$

The purpose of this study was to prospectively examine sagittal and coronal kinematics of a disc replacement using RSA. This study was designed as an adjunct to the randomized multicenter IDE study evaluating the effectiveness of ProDisc-L total disc replacement at our site.

\section{MATERIALS AND METHODS}

\section{Study Design}

Patients who had failed conservative measures and suffered from discogenic back pain were recruited as part of a prospective, multicenter, FDA-regulated IDE clinical trial investigating the ProDisc-L lumbar total disc replacement implant. The main inclusion criteria were that the patient had to have degenerative disc disease (DDD) in 1 or 2 vertebral level(s) between L3 and S1, have failed a minimum of 6 months of conservative treatment, have back and/or leg (radicular) pain, and have demonstrated a minimum Oswestry Low Back Pain Disability Questionnaire (Oswestry Disability Index (ODI) Version 2.0) score of $>40 \%$ (20/50) impairment. All subjects that were recruited at SUNY Upstate were asked to participate in the adjunct arm of the study and 12 subjects were enrolled.

The study was approved by the Institutional Review Board and Radiation Safety Board of SUNY Upstate Medical University and informed consent was obtained from each subject prior to participation. The subject demographics are shown in Table 1.

\begin{tabular}{lcccc}
\hline \multicolumn{5}{l}{ Table 1. Preoperative Demographics of Recruited Patients } \\
\hline Gender & N & Age (yrs) & Height (cm) & Weight (kg) \\
\hline Female & 5 & $43 \pm 9$ & $163 \pm 11$ & $67 \pm 13$ \\
Male & 7 & $44 \pm 7$ & $178 \pm 5$ & $82 \pm 13$ \\
Total & 12 & $43 \pm 8$ & $172 \pm 11$ & $76 \pm 15$ \\
\hline
\end{tabular}

Surgical Technique for Lumbar Total Disc Replacement Each patient undergoing lumbar total disc replacement was positioned in a supine, neutral position on a radiolucent operating table. Use of intra-operative fluoroscopy was mandatory. Exposure of the operative disc level(s) was through a standard mini-open retroperitoneal approach. A complete discectomy was performed, possibly including removal of the posterior entophytes and release of the posterior longitudinal ligament to ensure that the disc space had been mobilized. The cartilaginous endplates were carefully removed with curettes to maintain the integrity of the subchondral bony endplates.

The ProDisc-L instrumentation set contained 12 implant sizes. Implant trials were placed into the disc space intraoperatively to determine the appropriate footprint size (medium or large), lordotic angle $\left(6^{\circ}\right.$ or $\left.11^{\circ}\right)$, and disc height $(10 \mathrm{~mm}, 12 \mathrm{~mm}, 14 \mathrm{~mm})$. Under lateral fluoroscopic control, the trial was advanced to the posterior margin of the vertebral bodies; the chisel was advanced into the vertebral bodies using a mallet until it was fully seated against the adjustable stop on the trial. The ProDisc-L endplates were inserted in a collapsed fashion, with the keel following the slot cut by the chisel. Once the keel engaged the slot, rotational and translational position was automatically maintained, and the disc space was visualized fluoroscopically as the surgeon determined the cephalad-caudal angulation and depth. This implant's modular nature required only transient distraction for polyethylene insertion. 


\section{RSA Beads Placement}

For follow-up RSA analysis, 5 tantalum beads were inserted during surgery into each vertebra adjacent to the surgical level (Figure 1). The beads were located on the anterior surface of each body (2-3 beads) and inside the keel track (posterior and anterior). The bead sizes used were $1.0 \mathrm{~mm}$ for the single-level cases and 0.8 and $1.0 \mathrm{~mm}$ for the two-level cases (with the $0.8 \mathrm{~mm}$ between levels). The beads were implanted into the vertebrae using the appropriate insertion tool (RSA Biomedical Innovations AB, Umea, Sweden). Beads oriented in this manner during an anterior approach have been shown to have an accuracy of $0.1 \mathrm{~mm}$ and $0.5^{\circ}$ for translational and rotational measurements, respectively. ${ }^{23}$

\section{Figure 1.}
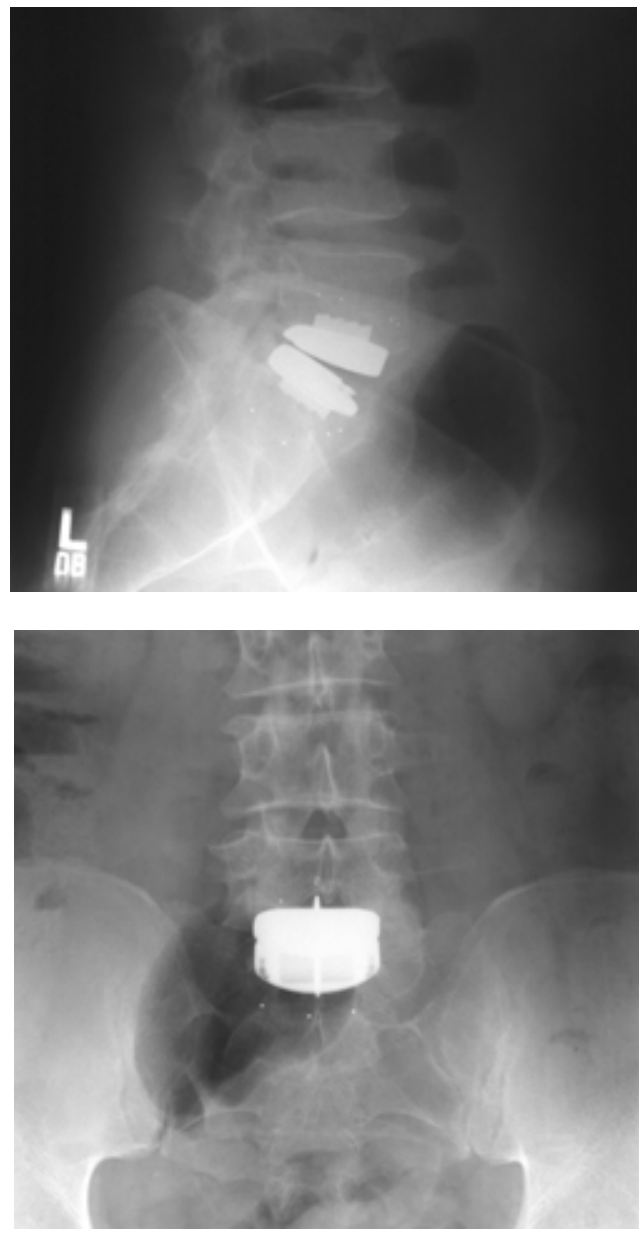

AP and lateral standing views of the lumbar spine demonstrating the position of the tantalum beads and the ProDisc-L total disc replacement.

\section{Postoperative Follow-up}

Patients were clinically examined at each follow-up time point, and routine standing radiographs were obtained at each time point. Visual analog score (VAS) and ODI outcome scores were collected at the preoperative and postoperative visits. Kinematic analysis of the intervertebral motions was performed by RSA.
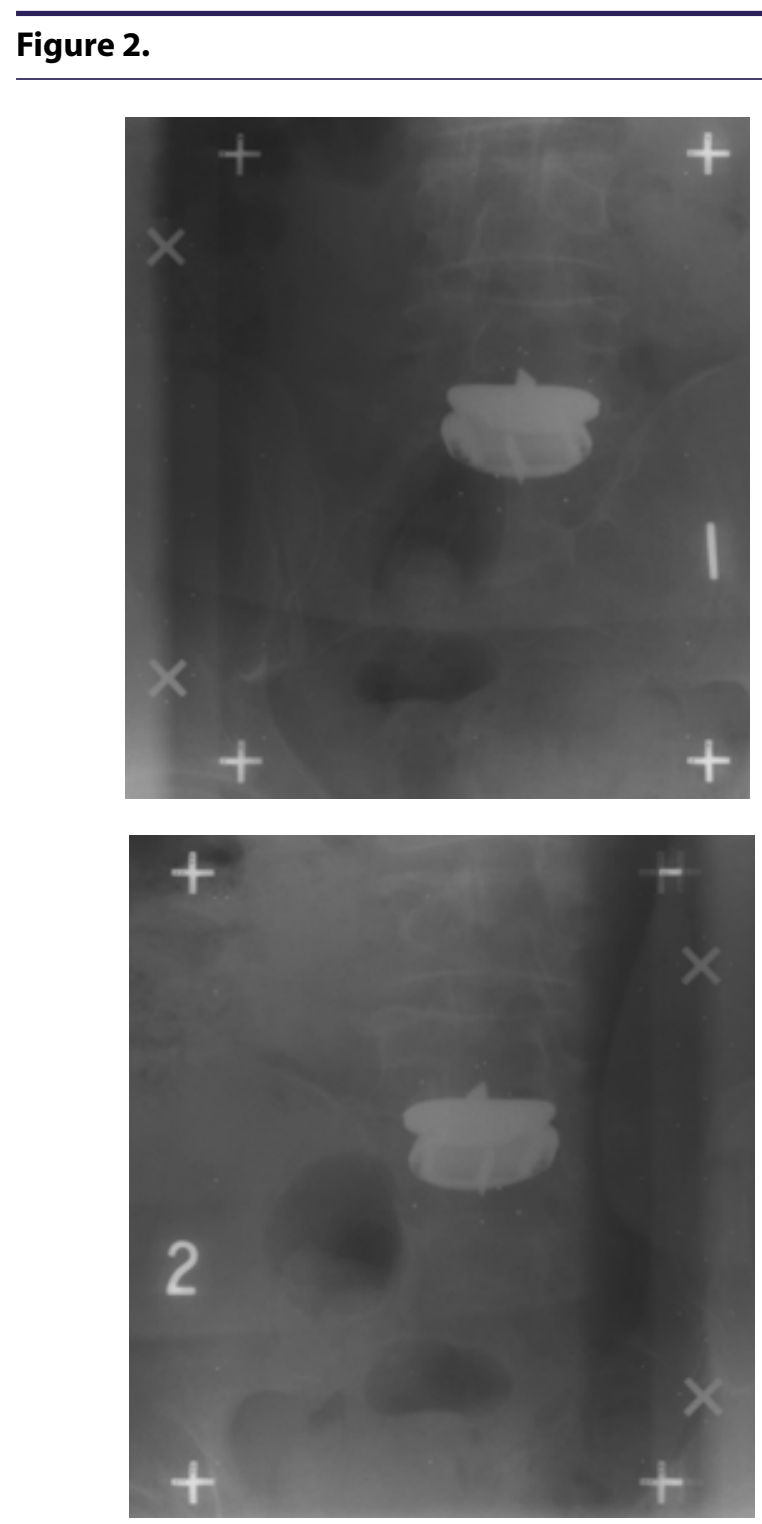

Biplanar radiographic examination of a subject with a single-level disc replacement demonstrating the position of the tantalum beads. The amount of radiation exposure was substantially less with these films when compared to routine lumbar films.

Subjects returned postoperatively at 1.5, 3, 6, and 12 months for follow-up clinical and RSA examinations.

For the RSA examination, simultaneous biplanar standing radiographic films were collected (Figure 2). Each pair of radiographs was obtained with the roentgen tubes at $40^{\circ}$ at the level of the lumbar spine. A wall-mounted plexiglass calibration cage with tantalum beads was placed between the subject and the films (RSA Biomedical Innovations AB). The cage defined the $3 \mathrm{D}$ coordinate system and was used to calculate the position of the roentgen foci and subsequent locations of the beads in each vertebra. The roentgen tubes were $1.6 \mathrm{~m}$ from the film and the beams of both tubes were collimated to the 2 grids on the cage (Figure 3 ). 
Figure 3.

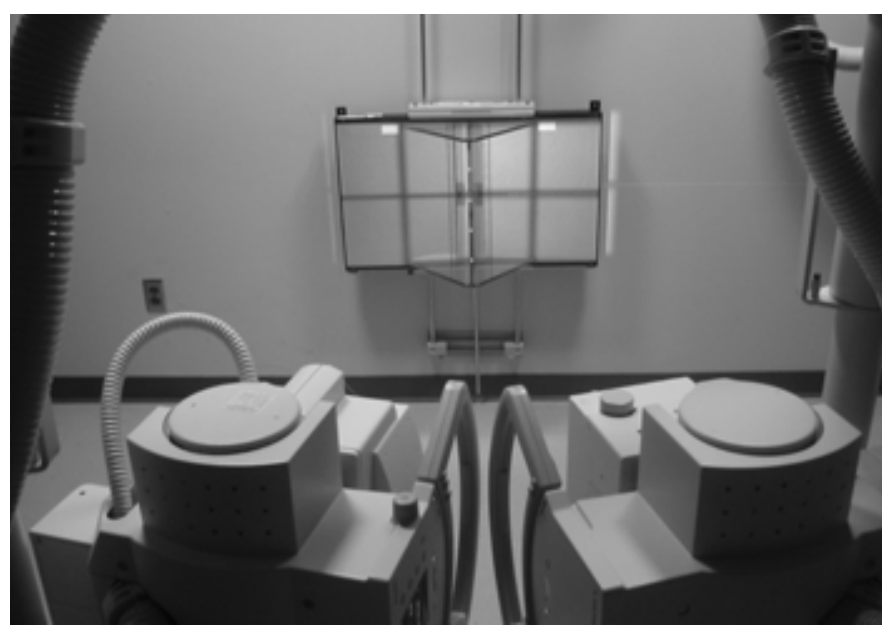

RSA examination was performed in a specialized radiographic suite with double roentgen tubes directed in $40^{\circ}$ diverging lines.

The amount of radiation exposure varied for each subject based on body habitus. The primary object of the radiographic examination was to enable an identification of the tantalum markers; therefore, anatomical resolution and contrast were less important than for conventional skeletal examination. In order to reduce the radiation dose, at the expense of contrast in the radiograph, exposure was performed at high kilovoltage techniques. High-speed (ISO) screens that allow less radiation were also utilized. A typical exposure technique for the exam in this study was $8 \mathrm{mAs} @ 150 \mathrm{kVp}$. A typical clinical radiograph would have a lower $\mathrm{kVp}$ (80-90) and higher mAs (40-50). The estimated exposure for a complete series of RSA biplanar films (neutral, flexion, extension, left and right bending) was calculated to be $155 \mathrm{mrem}$ per time point and was approved by the institutional radiation safety committee. This exposure is equivalent to less than 2 lateral clinical films.

\section{Kinematics Exam}

The objective of this study was to examine the active range of motion (ROM) in the sagittal and coronal plane following intervertebral disc replacement. A standardized protocol for positioning and movements were performed by all subjects and overseen by a single investigator. Following the neutral position, subsequent films were collected in the flexed, extended, and lateral bending (left and right) positions. Subjects received instruction, and each position was performed three times prior to film collection.

All films were digitally scanned and analyzed using UmRSA software (RSA Biomedical Innovations AB). In general, based on the calibration information, the $3 \mathrm{D}$ bead locations were determined, and the beads in each vertebra were clustered to examine the kinematics between levels. The ROM between levels was determined in the sagittal and coronal planes at each follow-up time point.
Twelve patients agreed to participate in a prospective clinical trial to examine the kinematics following ProDisc-L disc replacement using radiostereometric analysis (RSA) with an average age of $43 \pm 8$ years (Table 1). Four of the 12 patients that were enrolled in this study had a two-level disc replacement procedure performed for a total of 16 levels. Two of the 12 patients with a single-level procedure could not be followed by the RSA examination because of inadequate bead placement at the time of surgery. In addition, 2 subjects were not analyzed at 2 of the 4 follow-up time points.

In this cohort of patients, there was a gradual decrease in both the VAS and the ODI scores (Figure 4). The preoperative VAS score was $7.9 \pm 1.4 \mathrm{~cm}$ which decreased to $4.4 \pm 2.9 \mathrm{~cm}$ by the 12-month follow-up. There was also a decrease in the ODI from the preoperative level of $67 \pm 10$ to the postoperative level of $43 \pm 27$ at the 12-month follow-up visit. For both the ODI and the VAS clinical scores, there was a significant decrease $(P$ $<.001$ ) when comparing the preoperative score to each of the postoperative scores. Although there was a decrease in clinical

\section{Figure 4.}

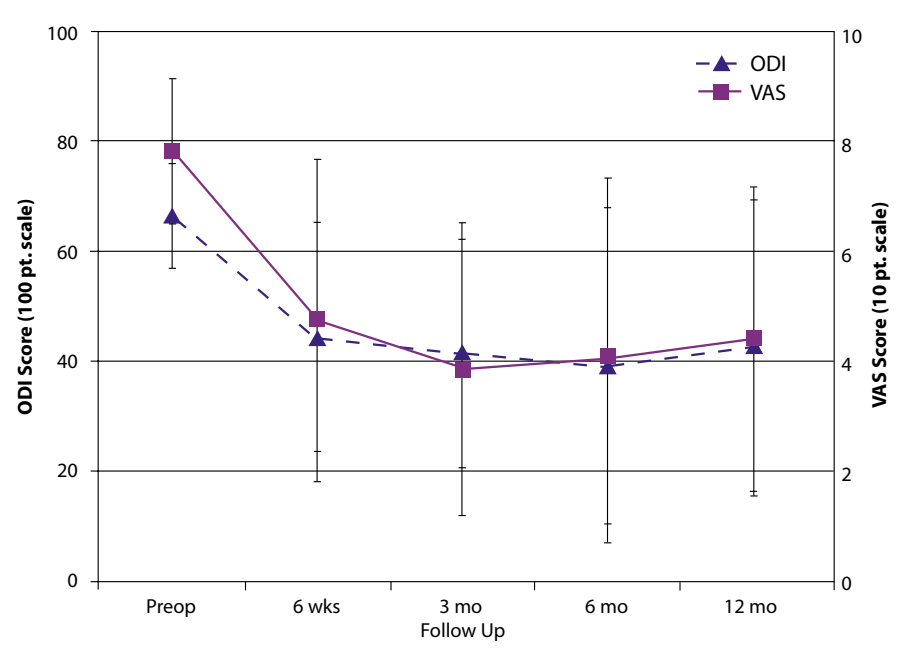

Mean ODI and VAS clinical scores at each of the follow-up time points. There was a significant decrease $(P<.001)$ seen in both VAS and ODI following the procedure.

scores over time, there were no significant differences between any of the scores from the postoperative time points.

The sagittal ROM following total disc replacement averaged $2.5^{\circ}$ at 1.5 months, $5.6^{\circ}$ at 3 months, $6.6^{\circ}$ at 6 months, and $6.3^{\circ}$ at 12 months. There was no significant difference in motion over the follow-up time points. There was a minimal amount of coupled motion in lateral bending noted in the axial plane (Ry) as demonstrated in Table 2. Although translation was seen in all 3 axes, no evidence of spondylolisthesis was noted on clinical films, and the translational motions measured using RSA did not correspond to pathologic motion in this group of patients. 
Table 2. Three-Dimensional ROM, Extension to Flexion

\begin{tabular}{ccccccc}
$\begin{array}{c}\text { Follow-up } \\
\text { (Months) }\end{array}$ & $\begin{array}{c}\mathbf{R x} \\
\text { Flex/Ext }\end{array}$ & $\begin{array}{c}\text { Rotations }\left(^{\circ}\right) \\
\mathbf{R y} \\
\text { Axial }\end{array}$ & $\begin{array}{c}\mathbf{R z} \\
\text { Lat } \\
\text { Bend }\end{array}$ & $\begin{array}{c}\text { Tx } \\
\text { Lateral }\end{array}$ & $\begin{array}{c}\text { Translation }(\mathbf{m m}) \\
\mathbf{T y} \\
\text { Vertical }\end{array}$ & $\begin{array}{c}\text { Tz } \\
\mathbf{A P}\end{array}$ \\
1.5 & $\mathbf{2 . 5}$ & -0.1 & 0.1 & -0.2 & -0.1 & 0.3 \\
3 & $\mathbf{5 . 6}$ & -0.6 & 0.5 & -0.2 & -0.4 & 1.5 \\
6 & 0.2 & -0.2 & -0.1 & -0.9 & 2.6 \\
12 & $\mathbf{6 . 6}$ & -0.4 & 0.2 & -0.1 & -1.2 & 2.4 \\
\hline
\end{tabular}

The 3-dimensional ROM results of patients following ProDisc- $L$ total disc replacement while moving from extension to flexion measured using RSA technique. Rotational motion in the $x$-axis (Rx) corresponds to the primary motion for the plane of interest (sagittal plane); other rotations (Ry and $\mathrm{Rz}$ ) are coupled motions.

Table 3. Three-Dimensional ROM, Lateral Bending

\begin{tabular}{ccccccc}
\hline $\begin{array}{c}\text { Follow-up } \\
\text { (Months) }\end{array}$ & $\begin{array}{c}\mathbf{R x} \\
\text { Flex/Ext }\end{array}$ & $\begin{array}{c}\text { Rotations }\left(^{\circ}\right) \\
\begin{array}{c}\text { Ry } \\
\text { Axial }\end{array}\end{array}$ & $\begin{array}{c}\mathbf{R z} \\
\text { Lat } \\
\text { Bend }\end{array}$ & $\begin{array}{c}\text { Tx } \\
\text { Lateral }\end{array}$ & $\begin{array}{c}\text { Translation (mm) } \\
\text { Ty } \\
\text { Vertical }\end{array}$ & $\begin{array}{c}\text { Tz } \\
\text { AP }\end{array}$ \\
1.5 & -1.2 & -1.1 & 2.9 & -1.5 & 0.4 & -0.2 \\
3 & -0.3 & -0.4 & $\mathbf{2 . 9}$ & -1.4 & 0.1 & 0.1 \\
6 & -1.5 & -0.1 & $\mathbf{3 . 2}$ & -1.5 & 0.2 & -0.2 \\
12 & 0.6 & -0.5 & $\mathbf{2 . 7}$ & -0.8 & -0.1 & 0.1 \\
\hline
\end{tabular}

The 3-dimensional ROM results of patients following ProDisc-L total disc replacement while moving from left to right lateral bending measured using RSA technique. Rotational motion in the Z-axis (Rz) corresponds to the primary motion for the plane of interest (coronal plane); other rotations ( $\mathrm{Rx}$ and $\mathrm{Ry}$ ) are coupled motions.

The lateral bending ROM following total disc replacement remained consistent over the 4 time points and averaged $3.0^{\circ}$ as shown in Table 3 . There was slightly more coupled motion seen in lateral bending movements when compared to sagittal movements.

There was a difference noted in the range of motion (not statistically significant) of the total disc devices placed at L5S1 when compared to the other levels in both the sagittal plane (Figure 5) and the coronal plane (Figure 6). The motion at the L4-5 level following disc replacement was consistently greater across all time points than the motion at the L5-S1 level for both sagittal $\left(6.4^{\circ}\right.$ versus $\left.4.2^{\circ}\right)$ and coronal bending $\left(4.2^{\circ}\right.$ versus $0.6^{\circ}$ ). At a number of time points, no motion within the RSA accuracy of $0.5^{\circ}$ could be detected at L5-S1.

Lumbar total disc replacement using the ProDisc-L device has been shown to be a very valid option for the treatment of lumbar degenerative disc disease with good clinical success as described by Zigler et al. ${ }^{12}$ In this prospective randomized study, ProDisc-L was demonstrated to be effective in the treatment of lumbar degenerative disc disease as measured by radiostereometric analysis. Our cohorts of patients were a small subgroup of the overall study and had very similar clinical outcomes as measured by ODI and VAS when compared to the overall patient population. ${ }^{12}$

The amounts of flexion/extension segmental ROM measured in this study for those with disc replacement were similar to other studies using planar radiography and less than the typical $10^{\circ}-20^{\circ}$ reported for normal ROM. ${ }^{24}$ However, flexion/ extension ROM was significantly greater in those patients with disc replacement (approximately $7^{\circ}$ to $10^{\circ}$ for L4-5 or L5-S1) compared to those with lumbar fusion (approximately $0^{\circ}$ to $4^{\circ}$ for L4-5 or L5-S1) described in the literature. ${ }^{13,25}$ In lateral bending, the amount of motion with disc replacement was less than the typical $6^{\circ}-16^{\circ}$ reported for normal ROM. ${ }^{26}$ Less motion following disc replacement in comparison to normal ROM could be a result of a number of factors including pain management of the patient, patient effort, positioning and fit of the implant, and differences in the disc or facet joint between diseased and normal segments.

Figure 5.

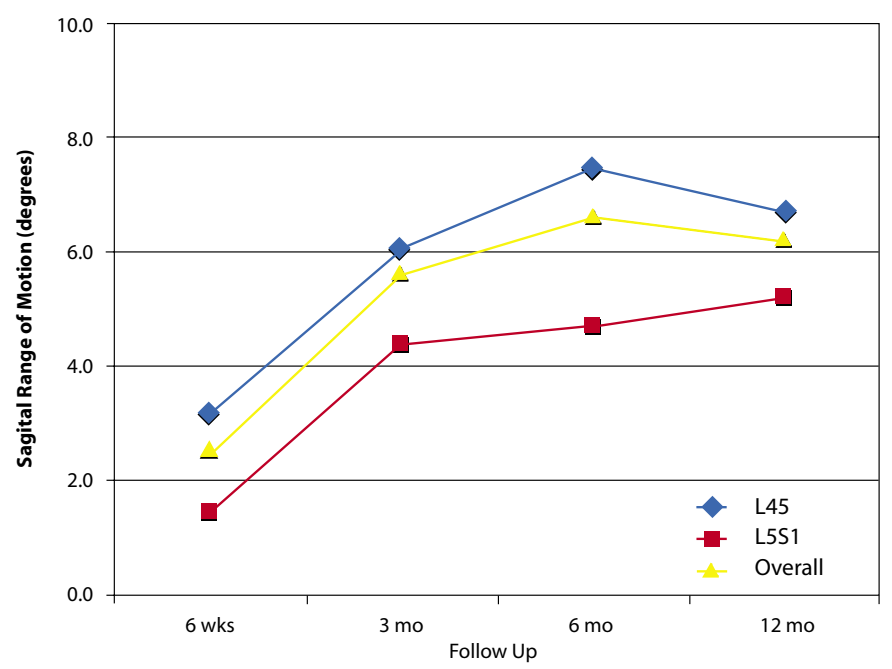

Mean lumbar sagittal ROM following total disc replacement demonstrates a gradual increase over the 1-year follow-up period. 
It is yet unclear how much motion is necessary to prevent adjacent segment disease. In this study the amount of motion was very specific to the operative level. A difference was noted between L5-S1 and the other operated levels with L5-S1 being less mobile. In a number of cases, the amount of motion at L5S1 was below the accuracy of the RSA method, especially in lateral bending as demonstrated in Figure 6 .

There are great advantages to the use of RSA in evaluation of spine ROM. RSA is the only method currently available that is

\section{Figure 6.}

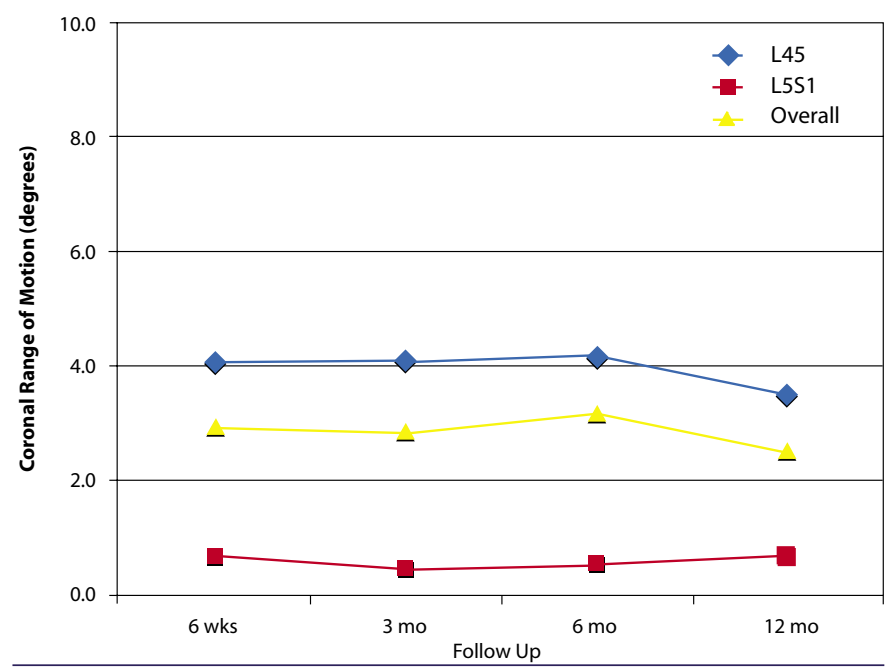

Mean lumbar coronal ROM following total disc replacement demonstrates similar magnitude during the 1-year follow-up period.

capable of adequately measuring 3D ROM of the spine. This capability is essential when evaluating the range of motion following implantation of a motion-sparing device. In addition, this technique is very accurate and precise and does not depend on the quality of radiographic films to identify anatomic landmarks. Future studies using RSA should be designed to study the quality of the motion following lumbar surgery with special attention to coupled motion.

Nathaniel R. Ordway, MS, PE, Celeste Abjornson, PhD, Jerry Calabrese, RT(R), CDT, Soo-An Park, MD, Bruce Fredrickson, MD, Kenneth Yonemura, MD, Hansen A. Yuan, MD, and Amir H. Fayyazi, MD

From the Department of Orthopedic Surgery, SUNY Upstate Medical University (Ordway, Calabrese, Park, Fredrickson, and Yuan); VSAS Orthopaedics, Institute for Advanced Healthcare (Fayyazi); Synthes Spine (Abjornson); Departments of Neurosurgery and Orthopedics, University of Utah (Yonemura)

Address correspondence and reprint requests to Nathaniel R. Ordway, MS, PE, Department of Orthopedic Surgery, SUNY Upstate Medical
University, 750 East Adams Street, Syracuse, NY 13201 (email: ordwayn@upstate.edu)

This manuscript was submitted September 11, 2007, and accepted for publication November 19, 2007.

Celeste Abjornson, $\mathrm{PhD}$, is an employee of Synthes Spine.

The authors thank Synthes Spine (research grant) and the Imaging Core at the Institute for Human Performance (IHP), SUNY Upstate Medical University.

This study was approved by the Institutional Review Board of and the Radiation Safety Board of SUNY Upstate Medical University.

This study was supported by a grant from Synthes Spine.

1. Madan SS, Boeree NR. Comparison of instrumented anterior interbody fusion with instrumented circumferential lumbar fusion. Eur Spine J. 2003;12(6):567-575.

2. Thomsen K, Christensen FB, Eiskjaer SP, Hansen ES, Fruensgaard S, Bunger CE. 1997 Volvo Award winner in clinical studies. The effect of pedicle screw instrumentation on functional outcome and fusion rates in posterolateral lumbar spinal fusion: a prospective, randomized clinical study. Spine. 1997;22(24):2813-2822.

3. Malmivaara A, Slatis P, Heliovaara M, et al. Surgical or nonoperative treatment for lumbar spinal stenosis? A randomized controlled trial. Spine. 2007;32(1):1-8.

4. Aiki $\mathrm{H}, \mathrm{Ohwada} \mathrm{O}$, Kobayashi $\mathrm{H}$, et al. Adjacent segment stenosis after lumbar fusion requiring second operation. J Orthop Sci. 2005;10(5):490-495.

5. Ghiselli G, Wang JC, Hsu WK, Dawson EG. L5-S1 segment survivorship and clinical outcome analysis after L4-L5 isolated fusion. Spine. 2003;28(12):1275-1280; discussion 1280 .

6. Hilibrand AS, Robbins M. Adjacent segment degeneration and adjacent segment disease: the consequences of spinal fusion? Spine J. 2004;4(supp1 6):190S-194S.

7. Errico TJ. Lumbar disc arthroplasty. Clin Orthop Relat Res. 2005(435):106117.

8. Gamradt SC, Wang JC. Lumbar disc arthroplasty. Spine J. 2005;5(1):95103.

9. Putzier M, Funk JF, Schneider SV, et al. Charite total disc replacement-clinical and radiographical results after an average follow-up of 17 years. Eur Spine J. 2006;15(2):183-195.

10. Fernstrom U. Arthroplasty with intercorporal endoprothesis in herniated disc and in painful disc. Acta Chir Scand Suppl. 1966;357:154-159.

11. Blumenthal S, McAfee PC, Guyer RD, et al. A prospective, randomized, multicenter Food and Drug Administration investigational device exemptions study of lumbar total disc replacement with the CHARITE artificial disc versus lumbar fusion: part I: evaluation of clinical outcomes. Spine. 2005;30(14):1565-1575; discussion E1387-1591.

12. Zigler J, Delamarter R, Spivak JM, et al. Results of the prospective, randomized, multicenter Food and Drug Administration investigational device exemption study of the ProDisc-L total disc replacement versus circumferential fusion for the treatment of 1-level degenerative disc disease. Spine. 2007;32(11):1155-1162; discussion 1163.

Downloaded from http://ijssurgery.com/ by guest on April 26, 2023 
13. Delamarter RB, Fribourg DM, Kanim LE, Bae H. ProDisc artificial total lumbar disc replacement: introduction and early results from the United States clinical trial. Spine. 2003;28(20):S167-175.

14. Zigler JE. Clinical results with ProDisc: European experience and U.S. investigation device exemption study. Spine. 2003;28(20):S163-166.

15. Tournier C, Aunoble S, Le Huec JC, et al. Total disc arthroplasty: consequences for sagittal balance and lumbar spine movement. Eur Spine J. 2007;16(3):411-421.

16. SariAli el H, Lemaire JP, Pascal-Mousselard H, Carrier H, Skalli W. In vivo study of the kinematics in axial rotation of the lumbar spine after total intervertebral disc replacement: long-term results: a 10-14 years follow up evaluation. Eur Spine J. 2006;15(10):1501-1510.

17. Lim MR, Girardi FP, Zhang K, Huang RC, Peterson MG, Cammisa FP, Jr. Measurement of total disc replacement radiographic range of motion: a comparison of two techniques. J Spinal Disord Tech. 2005;18(3):252256.

18. Cakir B, Richter M, PuhlW, Schmidt R. Reliability of motion measurements after total disc replacement: the spike and the fin method. Eur Spine J. 2006;15(2):165-173.

19. Lim MR, Loder RT, Huang RC, et al. Measurement error of lumbar total disc replacement range of motion. Spine. 2006;31(10):E291-297.

20. Gunnarsson G, Axelsson P, Johnsson R, Stromqvist B. A method to evaluate the in vivo behaviour of lumbar spine implants. Eur Spine $J$. 2000;9(3):230-234.

21. Axelsson P, Karlsson BS. Intervertebral mobility in the progressive degenerative process. A radiostereometric analysis. Eur Spine $J$. 2004;13(6):567-572.

22. Krijnen MR, Valstar ER, Smit TH, Wuisman PI. Does bioresorbable cage material influence segment stability in spinal interbody fusion? Clin Orthop Relat Res. 2006;448:33-38.

23. Brooks D, Ordway NR, Sacks J, Fredrickson BE. Evaluation of the accuracy and precision of Radiostereometric Analysis in Lumbar and Cervical Spine Surgery. Orthopaedic Research Society. 2001.

24. Huang RC, Girardi FP, Cammisa FP, Jr., Lim MR, Tropiano P, Marnay T. Correlation between range of motion and outcome after lumbar total disc replacement: 8.6-year follow-up. Spine. 2005;30(12):1407-1411.

25. Delamarter RB, Bae HW, Pradhan BB. Clinical results of ProDisc-II lumbar total disc replacement: report from the United States clinical trial. Orthop Clin North Am. 2005;36(3):301-313.

26. White AA, Panjabi MM. Clinical Biomechanics of the Spine. 2 ed. Philadelphia, Lippincott Williams \& Wilkins; 1990. 